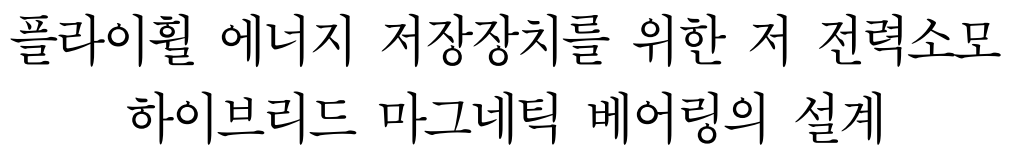

\title{
Design of Low Power Consumption Hybrid Magnetic Bearing for Flywheel Energy Storage System
}

\author{
김 우 연*.이 종 민*. 배 용 채**. 김 승 종† \\ Woo-Yeon Kim, Jong-Min Lee, Yong-Chae Bae and Seung-Jong Kim \\ (2010년 4월 28일 접수 ; 2010년 7월 28일 심사완료)
}

Key Words : Hybrid Magnetic Bearing(하이브리드 마그네틱 베어링), Flywheel Energy Storage System(플라이휠 에너지 저장장치), Permanent Magnetic Bearing(영구자석 베어링), Outer-rotor Type(외전형)

\begin{abstract}
For the application into a $1 \mathrm{kWh}$ flywheel energy storage system(FESS), this paper presents the design scheme of radial and axial hybrid magnetic bearings which use bias fluxes generated by permanent magnets. In particular, the axial hybrid magnetic bearing is newly proposed in this paper, in which a permanent magnet is arranged in axial direction so that it can support the rotor weight as well as provide a bias flux for axial magnetic bearing. Such hybrid magnetic bearings consume very low power, compared with conventional electromagnetic bearings. In this paper, to stably support a $140 \mathrm{~kg}$ flywheel rotor without contact, design process is explained in detail, and magnetic circuit analysis and three-dimensional finite element analysis are carried out to determine the design parameters and predict the performance of the magnetic bearings.
\end{abstract}

\section{1. 서 론}

에너지 저장용 플라이휠 장치는 크게 플라이휠을 포함한 회전체부, 전기 에너지와 회전 에너지의 상 호 변환을 위한 전동/발전기, 회전체를 지지하는 베 어링부로 구성된다. 플라이휠은 공기 마찰을 최소화 하기 위해서 진공 내에서 회전하는 경우가 많은데, 이 때는 구름 베어링과 같은 접촉식 베어링의 사용 이 불가능하여 마그네틱 베어링이나 초전도 베어링 과 같은 비접촉 베어링이 사용된다. 사실 초전도 베

† 교신저자; 정회원, 한국과학기술연구원 에너지메카닉스센터

E-mail : sjongkim@kist.re.kr

Tel : (02)958-5610, Fax : (02)958-5659

* 한국과학기술연구원 에너지메카닉스센터

** 정회원, 한국전력공사 전력연구원
어링을 쓰는 경우에도 낮은 감쇠력을 보완하기 위 해서 추가로 소형 마그네틱 베어링을 댐퍼로 사용 하는 경우가 많으므로, 에너지 저장용 플라이휠에서 마그네틱 베어링의 사용은 대세라고 말할 수 있다. 그러나, 마그네틱 베어링은 실시간 피드백 제어로써 어떤 상황에서도 안정성을 보장해야 한다는 부담 외 에도, 회전체를 장시간 부상시키기 위해 자체적으로 소모하는 전력이 크다는 단점이 있다. 안정성 보장을 위해서는 하드웨어적 잉여성(redundancy)과 회전체 역학 기반의 다양한 제어기 강건 설계 기법들이 연 구되어 왔고, 소모전력 문제를 극복하는 방법으로 는 영구자석이 정적인 힘(static force)을 제공하고 전자석이 제어력만을 담당하는 하이브리드 구조가 효과적인 것으로 알려져 있다. 이를 하이브리드 마 그네틱 베어링(hybrid magnetic bearing, $\mathrm{HMB}$ )이라 


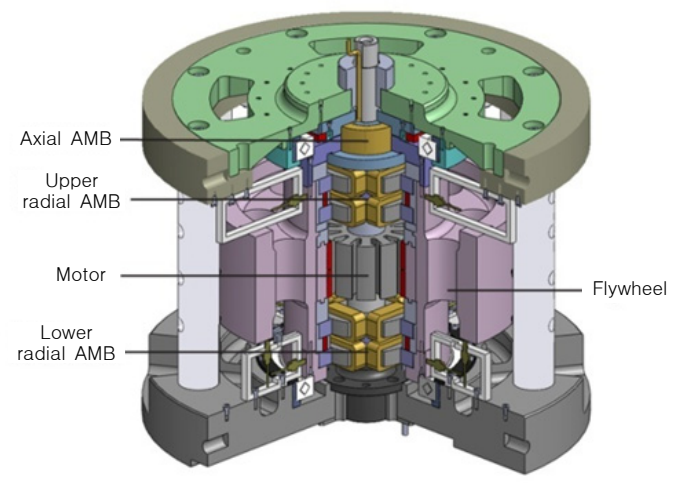

Fig. 1 Flywheel energy storage system

한다 ${ }^{(1 \sim 3)} \cdot \mathrm{HMB}$ 에서는 회전체가 부상 상태에서 진동 이 미소할 경우 이론적으로 소모 전력은 거의 없다.

이 논문에서는 $1 \mathrm{kWh}$ 급 에너지 저장용 플라이휠 장치에 장착되는 약 $140 \mathrm{~kg}$ 의 회전체를 지지하기 위한 $\mathrm{HMB}$ 의 설계과정을 소개한다. 플라이휠의 에 너지 저장 효율을 높이기 위해서는 주 질량 관성 모멘트가 커야 하기에 ${ }^{(4)}$, Fig. 1에 나타낸 바와 같이 회전체는 외전형(outer-rotor type)으로 설계되었으 며 축 방향 높이를 최소화하기 위한 구조를 갖는다. 특히, 축 방향 $\mathrm{HMB}$ 가 회전체의 자중을 감당하기 위한 영구자석과 일체화된 것이 구조적 특징이다. 이하 본론에서는 축 방향 및 반경 방향 $\mathrm{HMB}$ 의 구 조와 원리를 소개하고, 자기회로 해석과 유한요소 해석을 통해 설계 사양을 결정하는 과정과 최종적 으로 예측된 성능을 제시한다.

\section{2. 축 방향 $\mathrm{HMB}$ 의 설계}

\section{1 구조 및 원리}

이 논문에서 제안하는 축 방향 $\mathrm{HMB}$ 의 구조는 Fig. 2와 같다. 축 방향으로 자화된 링(ring)형 영구 자석이 회전체의 상부 표면과 일정한 공극을 두고 배치되어 회전체의 정적 하중을 지지하는 동시에, 축 방향 $\mathrm{HMB}$ 를 위한 바이어스 자속을 제공할 수 있도록 한 것이 구조적인 특징이다. 이러한 축 방향 $\mathrm{HMB}$ 는 하중 지지와 축 방향 제어가 동시에 가능하 여 하중 지지를 위한 영구자석을 추가로 장착하지 않아도 되므로 전체적으로 시스템의 크기를 줄이고, 무게를 경량화할 수 있는 이점이 있다.

Fig. 2에서 누설 자속이 없고 코어에서의 자기 저

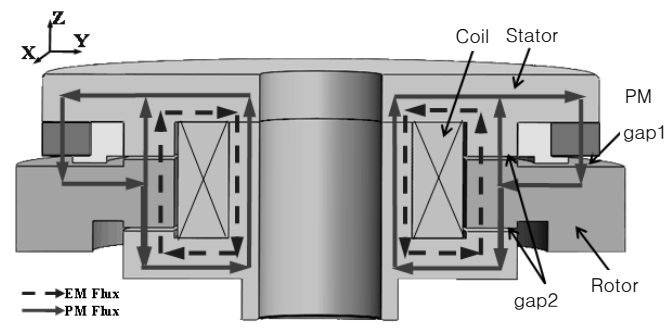

Fig. 2 Thrust HMB design for flywheel

항이 없는 이상적인 경우를 가정할 때, 영구자석에 의해 발생하는 바이어스 자속은 굵은 실선 화살표 로 표시된 경로를 따른다. 이 경로는 3 개의 공극을 포함하는데, 먼저 그림에서 gap1으로 표시된 공극 을 지나는 자속은 회전체 자중을 지지하는 $\mathrm{z}$ 방향 전자기력을 생성하고, 이후 양분되어 gap2로 표시 된 상하 공극을 지난다. 회전체의 부상이 정상 상태 일 때, 즉, 상하 gap2의 크기가 동일할 때는 양분되 는 바이어스 자속의 크기도 동일하다. 그러나 상하 gap2의 크기가 상이할 경우에는, 예를 들어 회전체 가 $-\mathrm{z}$ 방향으로 이동하여 하측 gap2가 상측 gap2보 다 좁아질 경우에는, 하측 gap2쪽으로 흐르는 자속 이 증가하고 자기력도 증가하여 회전체는 더욱 아 래쪽으로 끌려가게 된다. 즉, 바이어스 자속만으로 는 정상 상태를 유지할 수 없는 불안정성이 존재한 다. 이를 안정화하기 위해서, Fig. 2와 같이 중심축 주위로 도넛 형태의 코일이 감겨있다. 코일에서 발 생하는 제어 자속은 점선 화살표로 표시된 경로를 갖는데, 화살표의 방향은 코일의 전류 방향에 따라 바뀌고 자속의 세기는 전류의 크기에 비례한다. 그 림의 제어 자속 방향은 회전체를 위쪽으로 이동시 키기 위한 경우로서, 상측 gap2에서는 제어 자속과 바이어스 자속의 방향이 일치하여 전자기력이 증가 하고, 하측 gap2에서는 그들의 방향이 반대가 되어 전자기력이 감소한다. 제어 자속이 증가하여 상측 공극에서의 전자기력이 더 커지면 회전체는 위쪽으 로 이동한다. 즉, 회전체의 상하 방향(축 방향) 변위 발생 시에 제어 전류를 적절히 제어하면 회전체를 정상 상태 위치로 복원시키는 것이 가능하다.

한편, 회전체가 정상 상태 위치를 유지하고 있다 면 제어 전류는 거의 $0 \mathrm{~A}$ 가 될 것이다. 그러나, 정상 상태에서 영구자석에 의한 축 방향 자기력이 회전 체의 자중과 일치하도록 영구자석과 공극의 크기를 


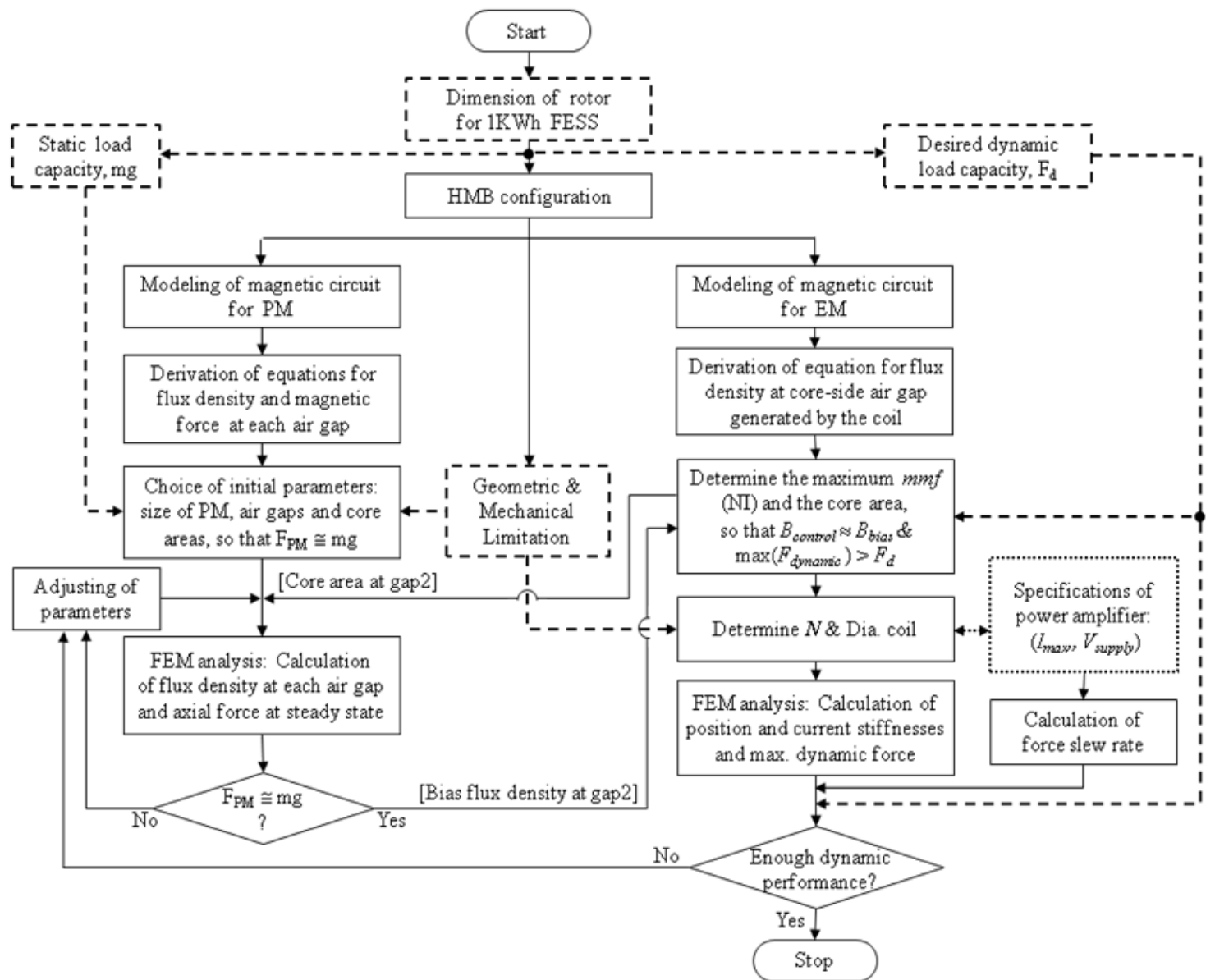

Fig. 3 Flow chart for the design of thrust HMB

정확히 설계하고 제작하기란 불가능에 가깝다. 그러 므로 그 두 힘 사이의 차이를 보상할 필요성은 항 상 발생하며, 이를 축 방향 $\mathrm{HMB}$ 에서 보상하기 위 하여 축 방향 코일에 약간의 오프셋(offset) 전류를 지속적으로 인가해야 한다. 이는, 축 방향 $\mathrm{HMB}$ 의 영구자석 설계 정확도에 따라 전체 플라이휠 시스 템의 소모전력이 좌우될 수 있음을 의미한다.

\section{2 자기회로 해석 및 설계 변수 선정}

Fig. 3은 이 논문에서 제안하는 축 방향 $\mathrm{HMB}$ 의 설계 과정을 보여주는 플로우차트(flow chart)이다. 우선, 플라이휠 시스템의 에너지 저장 용량에 따라 회전체의 형상, 크기와 무게, 회전속도, 그리고 Fig. 1 과 같은 대략적인 구조 등이 정해지면, 먼저 축 방 향 $\mathrm{HMB}$ 의 영구자석과 코일에 대한 자기회로의 해 석을 수행한다. 이는 축 방향 $\mathrm{HMB}$ 가 적절한 정적
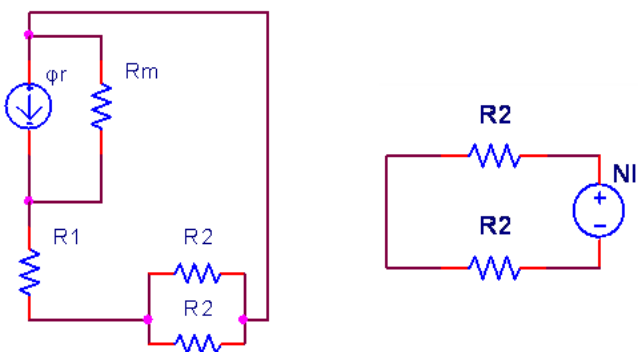

(a) Flux generated by PM

(b) Flux generated by EM

Fig. 4 Magnetic circuits of thrust HMB

(static), 동적 부하용량을 갖도록, 영구자석 크기와 공극의 크기, 코어 면적, 권선수 등에 대한 초기 설 계치를 얻기 위함이므로, 누설 자속과 프린징 (fringing) 효과 및 코어에서의 자기저항(reluctance) 
을 무시한, 가장 단순화된 자기회로를 고려한다. Fig. 4의 (a)는 Fig. 2에 나타낸 축 방향 HMB에서 영구자석에 의해 발생하는 바이어스 자속에 대한 자기회로이고, (b)는 코일에 흐르는 제어 전류에 의 해 생성되는 제어 자속에 대한 자기회로이다. Fig. 4 의 (a)에서 영구자석은 내부 자기저항 $R_{m}$ 을 갖는 자속 소스(flux source)로 모델링되었다. Fig. 2에 표 시된 공극 gap1과 gap2의 자기저항을 각각 $R_{1}, R_{2}$ 라 하면, gap1을 지나는 바이어스 자속은 식 (1)과 같이 표현된다.

$$
\phi=\phi_{\mathrm{r}} \frac{R_{m}}{R_{1}+\frac{R_{2}}{2}+R_{m}}
$$

여기서, $\phi_{\mathrm{r}}=B_{r} A_{m}$ 이고,

$$
R_{m}=\frac{l_{m}}{\mu_{0} A_{m}}, R_{1}=\frac{g_{1}}{\mu_{0} A_{1}}, R_{2}=\frac{g_{2}}{\mu_{0} A_{2}}
$$

이다. $B_{r}$ 은 영구자석의 특성인 잔류 자속밀도(네오 디뮴 자석의 경우, 약 $1.3 \mathrm{~T}$ )이고, $g_{1}, g_{2}$ 는 각각 공 극 gap1과 gap2의 크기이며, $l_{m}$ 과 $A_{m}$ 은 영구자석의 길이와 단면적을, $A_{1}$ 과 $A_{2}$ 는 각각 공극 gap1과 gap2에서의 코어 단면적을, $\mu_{0}$ 는 진공상태에서의 투자율 $\left(=4 \pi \times 10^{-7}\right)$ 을 나타낸다. 식 (1)과 (2)로부터 각 공극에서의 자속밀도, $B_{1}$ 과 $B_{2}$, 그리고 전자기 력, $F_{1}$ 과 $F_{2}$ 를 다음과 같이 유도할 수 있다.

$$
\begin{aligned}
& B_{1}=B_{\mathrm{r}} \cdot \frac{1}{\frac{g_{1}}{l_{m}}+\frac{g_{2}}{2 l_{m}} \cdot \frac{A_{1}}{A_{2}}+\frac{A_{1}}{A_{m}}} \\
& B_{2}=\frac{B_{\mathrm{r}}}{2} \cdot \frac{1}{\frac{g_{1}}{l_{m}} \cdot \frac{A_{2}}{A_{1}}+\frac{g_{2}}{2 l_{m}}+\frac{A_{2}}{A_{m}}} \\
& F_{n}=\frac{B_{n}^{2} A_{n}}{2 \mu_{0}}, \text { 여기서 } n=1 \text { 또는 } 2 .
\end{aligned}
$$

이어서, $F_{1}$ 이 정상 상태에서 회전체의 자중 $(=140$ $\mathrm{kg}$ )과 거의 같아지도록 설계변수, $g_{1}, g_{2}, l_{m}, A_{m}$, $A_{1}, A_{2}$ 들의 값을 선정해야 하는데, 설계변수의 수가 많으므로 몇 가지 설계지침을 추가로 고려한다. 우 선, 코어에서의 포화 자속밀도가 $1.2 \mathrm{~T}$ 정도임을 감
안하여, 정상 상태에서의 $B_{1}$ 을 $1.0 \mathrm{~T}$ 로 설정한다. 이 값이 너무 작아지면 자중 지지를 위한 영구자석 의 크기가 증가하므로 바람직하지 않고, 너무 크면 회전체 변위에 의해 공극이 좁아질 경우 자속밀도 가 증가하여 자속 포화가 발생할 수 있다. 이제 식 (5)로부터 $A_{1} \gg 3450 \mathrm{~mm}^{2}$ 임을 얻을 수 있고, 프린 징 효과를 무시했으므로 $A_{m}$ 도 $A_{1}$ 과 거의 같다고 놓을 수 있다.

한편, Fig.4(b)에 도시한 코일에 의해 발생하는 제어 자속에 대한 자기회로에서, 공극 gap2에서의 제어 자속밀도 $B_{c}$ 는 다음과 같이 얻어진다.

$$
B_{c}=\frac{\phi_{c}}{A_{2}}=\frac{N I}{2 A_{2} R_{2}}=\frac{\mu_{0} N I}{2 g_{2}}
$$

여기서 $N$ 은 권선수이고 $I$ 는 제어 전류이다. 그리고, gap1에서 발생하는 영구자석에 의한 자기력 $F_{1}$ 이 정확히 자중과 상쇄된다는 가정 하에, 정상 상태에 서 gap2에서 발생하는 최대 축 방향 전자기력은 식 (7)과 같이 유도될 수 있다.

$$
\begin{aligned}
F_{\text {max }} & =\frac{\left(B_{2}+B_{c}\right)^{2} A_{2}}{2 \mu_{0}}-\frac{\left(B_{2}-B_{c}\right)^{2} A_{2}}{2 \mu_{0}} \\
& =\frac{\left(B_{\max }\right)^{2} A_{2}}{2 \mu_{0}} \approx 5.73 \times 10^{5} A_{2}
\end{aligned}
$$

식 (7)은 gap2의 한 쪽 공극에서는 $B_{2}$ 와 $B_{c}$ 의 합 이 최대값, 즉, 포화 자속밀도에 이르고, 다른 쪽 공극에서는 그 둘이 서로 상쇄되는 경우에, 축 방향 전자기력이 최대가 되고, 그 크기는 $A_{2}$ 에 비례함을 나타낸다. 여기서, 최대 축 방향 전자기력은 동적 부하용량을 의미하는데, 반경 방향 $\mathrm{HMB}$ 와 달리 축 방향 $\mathrm{HMB}$ 에 있어서는 불균형력과 같은 진동 유발 요인의 영향이 크지 않으므로, 보통 회전체 무게의 $1 \sim 1.5$ 배가 되도록 $A_{2}$ 를 선정한다. 예를 들어, $A_{2}=A_{1}$ 로 하면 이러한 힘 조건을 대략 만족한다. 그 리고 식 (3)과 식 (4)에서 $A_{1}=A_{2}$ 인 경우에 $B_{2}=B_{1} /$ $2=0.5 \mathrm{~T}$ 가 됨을 알 수 있다. 이는 상세 해석을 위한 초기값일 뿐, 공간적인 제약이 있는 경우나, 바이어 스 자속밀도 $B_{1}$ 대비 $B_{2}$ 를 증가시킬 필요가 있는 경우에는 $A_{2}$ 를 적절히 감소시키면 된다.

다음으로 공극의 크기와 영구자석의 높이를 선정 한다. 우선, 회전체가 기울어질 때 고정자와의 접촉 
가능성과 가공 및 조립 공차 등을 고려하여 비상 베어링과 회전체 사이의 축 방향 간극은 $0.3 \mathrm{~mm}$ 로 하였다. 이 경우 일반적인 자기 베어링에서는 정상 상태 공극 $g_{2}$ 를 그 두 배인 $0.6 \mathrm{~mm}$ 정도로 설계하 지만, 이 시스템과 같이 영구자석에 의한 바이어스 자속의 경로가 gap2에서 상하로 나뉘는 경우에는, $g_{2}$ 가 작으면 회전체의 축 방향 변위 발생 시에 상 하 공극의 차이가 증가하여, 변위에 따른 상하 공극 에서의 바이어스 자속밀도의 차이도 커진다. 이는 시스템의 불안정한 강성의 증가를 의미하며, 심한 경우 심각한 비선형성을 초래한다. 반대로 $g_{2}$ 가 너 무 크면 Fig. 4(b)와 식 (2)에서 알 수 있듯이 코일 이 포함된 자기회로에서 자기저항이 증가하여 제어 전류 소모량이 증가하므로 바람직하지 않다. 이를 고려하여 이 시스템에서 $g_{2}$ 는 $1 \mathrm{~mm}$ 로 선정하였다. gap1 측의 정상상태 공극 $g_{1}$ 도 비슷한 선정 과정을 거친다. 앞서 설명한대로 gap1에서 발생하는 자기 력은 정상상태에서 회전체 자중과 일치하도록 설계 되는데, 회전체의 축 방향 변위가 발생하더라도 이 관계가 최대한 유지되는 것이 바람직하다. 이를 위 해서는 $g_{1}$ 이 발생 가능 변위보다 충분히 커야 한다. 그러나 $g_{1}$ 이 너무 크면 누설 자속이 증가하고 영구 자석의 크기가 증가한다. 이들을 고려하여 $g_{1}$ 은 3 $\mathrm{mm}$ 로 선정하였다. 한편, 영구자석의 높이 $l_{m}$ 은 앞 서 선정된 변수들을 식 (3)에 대입하여 구할 수 있 다. 계산 결과는 $11.67 \mathrm{~mm}$ 이지만, 영구자석의 제작 편의성 등을 고려하여 $l_{m}$ 의 초기치는 $12 \mathrm{~mm}$ 로 하 였다.

끝으로, 코일 권선수와 최대 제어 전류의 곱으로 나타나는 최대 기자력(magneto-motive force)을 식 (6)에서 구할 수 있다. 이 식에서 주목할 점은 $B_{c}$ 는 $A_{2}$ 와 무관할 뿐만 아니라, 회전체의 축 방향 변위 가 발생하여도 gap2의 위아래 공극의 합은 일정하 므로 $B_{c}$ 는 변하지 않는다는 점이다. 문제는 $B_{c}$ 의 최대값 산정 방법이다. 앞에서, 정상 상태에서 gap2 측 상하 공극의 바이어스 자속밀도 $B_{2}$ 를 $0.5 \mathrm{~T}$ 로 하였으므로, $B_{c}$ 의 최대값도 $0.5 \mathrm{~T}$ 로 함이 타당할 것 같지만, $B_{c}$ 의 최대값은 회전체의 축 방향 진폭이 최대일 때 공극이 좁은 쪽의 자속밀도가 $0 \mathrm{~T}$ 가 되 는 수준으로 설정하는 것이 합리적이다. Fig. 2에서 회전체가 $+\mathrm{Z}$ 방향으로 $z$ 만큼 이동하였을 때, 자기 회로 해석에 의하여 gap2의 상하 공극에서의 자속
밀도는 각각 식 (8), 식 (9)와 같이 유도된다.

$$
\begin{aligned}
& B_{2,+\mathrm{z}}=B_{\mathrm{r}} \frac{g_{2}+z}{2 g_{2}} \cdot \frac{1}{\frac{g_{1}-z}{l_{m}} \cdot \frac{A_{2}}{A_{1}}+\frac{g_{2}{ }^{2}-z^{2}}{2 g_{2} l_{m}}+\frac{A_{2}}{A_{m}}} \\
& B_{2,-\mathrm{z}}=B_{\mathrm{r}} \frac{g_{2}-z}{2 g_{2}} \cdot \frac{1}{\frac{g_{1}-z}{l_{m}} \cdot \frac{A_{2}}{A_{1}}+\frac{g_{2}{ }^{2}-z^{2}}{2 g_{2} l_{m}}+\frac{A_{2}}{A_{m}}}
\end{aligned}
$$

비상 베어링과의 간극이 $0.3 \mathrm{~mm}$ 이므로, 즉, 축 방향 최대 변위가 $0.3 \mathrm{~mm}$ 이므로, $\mathrm{z}=0.3 \mathrm{~mm}$ 를 위 식들에 대입하면, $B_{2},+\mathrm{z}$ 와 $B_{2},-\mathrm{z}$ 는 각각 $0.669 \mathrm{~T}$ 와 $0.360 \mathrm{~T}$ 로 계산되고, $\mathrm{z}=-0.3 \mathrm{~mm}$ 인 경우에는 각각 $0.347 \mathrm{~T}$ 와 $0.644 \mathrm{~T}$ 가 얻어진다. 전자의 경우의 상하 자속밀도들이 후자의 경우보다 다소 큰 것은 gap1 의 공극이 감소하여 전체 자속이 증가하기 때문이 다. $B_{c}$ 의 최대값은 위에서 구한 네 가지 결과 중 가장 큰 값인 $0.67 \mathrm{~T}$ 로 설정한다.

한편, 이 때 요구되는 기자력은 식 (6)으로부터 대략 1,066 A·turn임을 알 수 있다. 앞서 언급하였듯 이 축 방향 $\mathrm{HMB}$ 에서는 동적 부하용량이 그리 크 지 않아도 되므로, 힘 슬루율(force slew rate)은 고 려하지 않고 코일 권선 공간과 전력 증폭기의 용량 을 고려하여 권선수와 최대 전류를 결정한다. 그 결 과, 코일 권선수는 200 회, 최대 전류는 $5 \mathrm{~A}$ 로 설정 하였다.

\section{$2.3 \mathrm{FEM}$ 해석에 의한 검증 및 성능 예측}

앞 절에서 설정한 각 변수들은 손실을 고려하지 않은 모델에 의한 것이므로, 설계 형상에 대한 보다

\begin{tabular}{|c|c|c|}
\hline \multicolumn{2}{|r|}{ Parameter } & Value \\
\hline \multirow{4}{*}{ PM size } & Height(mm) & 10 \\
\hline & Outer dia.(mm) & 164 \\
\hline & Inner dia.(mm) & 136 \\
\hline & Cross-sectional area $\left(\mathrm{mm}^{2}\right)$ & 6,600 \\
\hline \multirow{3}{*}{$\begin{array}{l}\text { Core size of } \\
\text { stator and } \\
\text { rotor } \\
\text { at the gap2 }\end{array}$} & Outer dia.(mm) & 116 \\
\hline & Inner dia.(mm) & 80 \\
\hline & Cross-sectional area $\left(\mathrm{mm}^{2}\right)$ & 5,540 \\
\hline \multirow{2}{*}{ Air gap size } & $\operatorname{gap} 1(\mathrm{~mm})$ & 3 \\
\hline & gap2(mm) & 1 \\
\hline
\end{tabular}

Table 1 Specification of thrust HMB 
정확한 해석을 통하여 설계 변수를 조정하는 과정 의 반복이 필요하다. 이를 위하여 3 차원 $\mathrm{FEM}$ 해석 소프트웨어인 Maxwell v.11 3D를 이용하였다. 해 석 결과, 누설 자속과 프린징 효과 등, 자기회로 해 석에서 무시되었던 효과들에 의해 자속밀도가 약 $15 \%$ 낮은 값으로 얻어졌다. 이를 증가시키기 위해 서, 각 공극의 크기는 앞 절에서 선정한 값을 유지 한 채, 영구자석 및 코어의 면적을 증가시켰다. 최종 설계값들을 Table 1 에 정리하였다. Table 1 의 값들을 이용한 $\mathrm{FEM}$ 해석 결과에서, 공극 gap1에서의 자속 밀도 $B_{1}$ 은 $0.788 \mathrm{~T}$ 이고, gap2측의 위쪽 공극에서의 정상상태 바이어스 자속 밀도 $B_{2}$ 는 $0.478 \mathrm{~T}$, 아래쪽 공극의 $B_{2}$ 는 $0.399 \mathrm{~T}$ 이었다. 참고로, 동일한 값들을 식 (2)와 (3)에 넣어 계산한 결과는 $B_{1}$ 가 $0.898 \mathrm{~T}$, $B_{2}$ 는 $0.542 \mathrm{~T}$ 이었다. 한편, gap1에서의 영구자석 자 기력은 $1,466 \mathrm{~N}$ 으로서 자중 $(140 \mathrm{kgf})$ 보다 약 $6.8 \%$

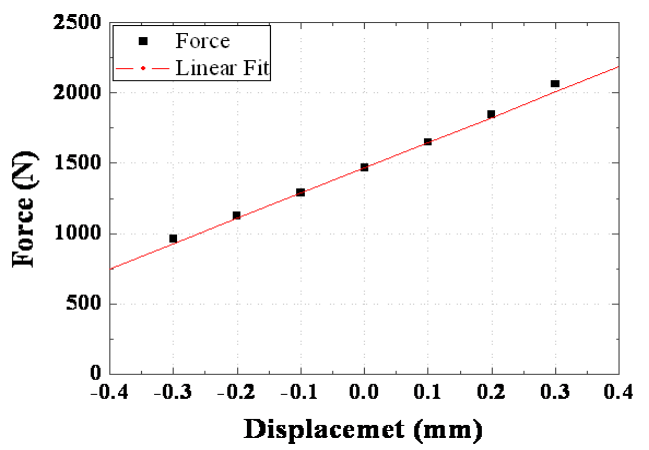

Fig. 5 Variation of magnetic force according to rotor displacement when $I=0 \mathrm{~A}$ in thrust $\mathrm{HMB}$

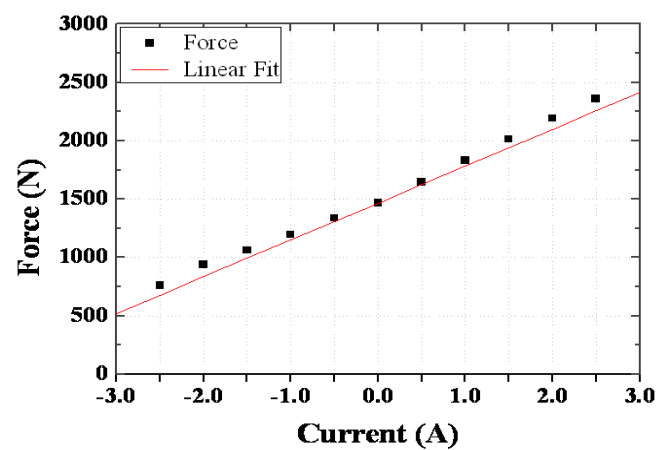

Fig. 6 Variation of magnetic force according to control current at normal state in thrust HMB
큰 값이다. 이는 실제 제작된 시스템에서 발생하는 힘이 $\mathrm{FEM}$ 결과보다 다소 작게 얻어지는 경험을 반 영한 것이다.

최종 설계된 축 방향 $\mathrm{HMB}$ 에 대하여, 회전체의 축 방향 변위 및 제어 전류의 변화에 따른 전자기 력의 변화를 $\mathrm{FEM}$ 을 이용하여 예측한 결과를 Fig. 5 와 6 에 도시하였다. 그림에서 보듯이 계산 결과는 선형적으로 근사가 가능한데, 두 직선의 기울기는 각각 위치강성계수와 전류강성계수로 정의되는 상 수들로서 그 값은 각각 $1.801 \times 10^{6} \mathrm{~N} / \mathrm{m}$ 와 315.9 $\mathrm{N} / \mathrm{A}$ 로 계산되었다. 두 그림에서 나타낸 힘에는 gap1에서의 자기력이 포함되어 있기에 변위와 전류 가 없는 상태에서 발생하는 $1,466 \mathrm{~N}$ 이 기준이 되었 다. 잘 알려진 바와 같이, 위의 위치강성계수는 불 안정한 강성이다. 피드백 제어기를 포함한 폐루프 시스템의 안정된 강성계수는 피드백 제어 이득에 따라 좌우되지만, 최대 변위 $0.3 \mathrm{~mm}$ 일 때 최대 전 류 $5 \mathrm{~A}$ 가 흐른다고 가정하면, 다음과 같이 대략 추 정할 수 있다.

$$
\begin{aligned}
K & =315.9 \times \frac{5}{0.3 \times 10^{-3}}-1.801 \times 10^{6} \\
& =3.464 \times 10^{6}(\mathrm{~N} / \mathrm{m})
\end{aligned}
$$

그러면, 회전체의 축 방향 고유진동수는 약 24.5 $\mathrm{Hz}$ 로 예측된다. 제어기 설계 및 시스템 동특성에 관한 자세한 내용은 후속 논문에 기술하기로 한다.

\section{3. 반경 방향 $\mathrm{HMB}$ 설계}

\section{1 구조 및 원리}

Fig. 7은 이 논문에서 설계된 반경 방향 $\mathrm{HMB}$ 의 구조 및 자속 경로를 나타낸다. 이와 같은 구조는 잘 알려진 호모폴라(homopolar)형 $\mathrm{HMB}^{(3)}$ 로서 외전 형(outer rotor type)이고 바이어스 자속을 생성하는 영구자석이 회전체 측에 끼워져 있는 경우이다. 동 일한 코일이 감긴 4 개의 코어가 $90^{\circ}$ 간격으로 배치 되어 있는 고정자 주위에 링(ring) 형상의 회전자가 있는 구조가 두 층을 이루고 있는데, 두 회전자 사 이에는 축 방향으로 자화된 영구자석이 끼워지고, 두 고정자는 자성체 재질의 중심축으로 연결된 구 조이다. 그러면, 영구자석에서 발생한 바이어스 자 속은 그림에서 실선으로 표시된 '상층 회전자 $\rightarrow 4$ 
개의 공극 $\rightarrow$ 4개의 상층 고정자 코어 $\rightarrow$ 중심축 $\rightarrow$ 개의 하층 고정자 코어 $\rightarrow$ 4개의 공극 $\rightarrow$ 하층 회전자 $\rightarrow$ 영구자석 $\mathrm{S}$ 극'의 경로를 갖는다. 반면에 코일에 의한 제어 자속의 경우에는, 서로 반대방향 에 위치한 코일들이 동일한 방향으로 자속을 생성 하도록 연결되어 있어서, Fig. 7에서 점선으로 표시 된 바와 같이, '한 쪽 코어 $\rightarrow$ 공극 $\rightarrow$ 회전자(양쪽 으로 반원을 그리며 반대편으로 이동) $\rightarrow$ 공극 $\rightarrow$ 반대쪽 코어 $\rightarrow$ 고정자 중심'의 경로를 갖는다. 상 층과 하층의 제어자속의 경로는 독립적이며 방향은 서로 반대이다. 이로써, 상하층 공히, 한 쪽 공극에 서는 바이어스 자속과 제어 자속의 방향이 동일하 고 반대쪽 공극에서는 두 자속의 방향이 반대가 된 다. 예를 들어, Fig. 7에서 좌측의 공극에서는 두 자 속의 방향이 일치하고 우측 공극에서는 반대 방향 이 되므로, 좌측 공극에서의 전자기력이 증가하여

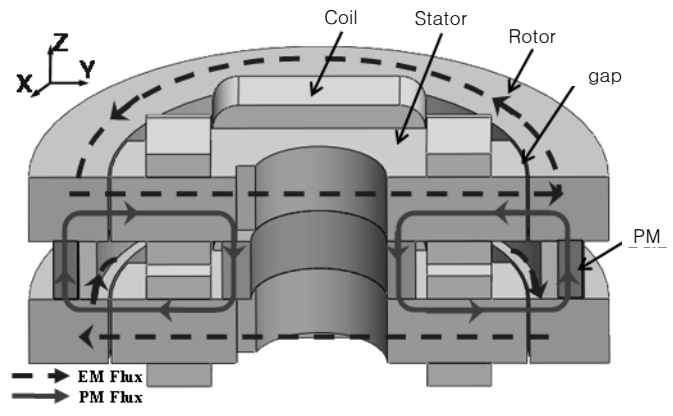

Fig. 7 Flux paths in radial HMB

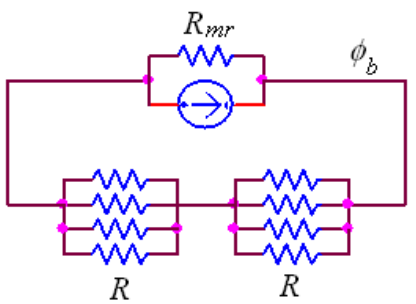

(a) Flux is generated by PM

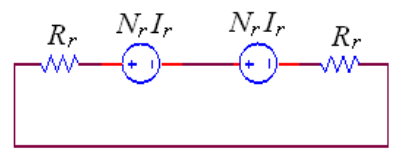

(b) Flux is generated by EM

Fig. 8 Electromagnetic circuit of radial HMB
회전체는 우측(+Y방향)으로 이동한다. 이와 같이, 제어 전류의 방향과 크기를 조절하여 양쪽 공극에 서의 자속의 크기를 제어함으로써 회전체를 중심 위치에 부상시킬 수 있다.

\section{2 자기회로 해석 및 설계 변수 선정}

반경 방향 $\mathrm{HMB}$ 의 설계과정은 회전체 자중을 감 당하는 정적인 힘에 대한 고려만 제외하면 Fig. 3과 유사하다. Fig. 8(a)는 영구자석에 대한 자기회로이 다. 정상 상태에서 하나의 고정자 코어를 지나는 바 이어스 자속은 다음과 같이 얻어진다.

$$
\phi_{c}=\phi_{\mathrm{r}} \frac{R_{m r}}{2 R_{r}+4 R_{m r}}
$$

여기서, 반경 방향 내부저항 $R_{m r}$ 과 하나의 코어 공 극에서의 자기저항 $R_{r}$ 은

$$
R_{m r}=\frac{l_{m r}}{\mu_{0} A_{m r}}, R_{r}=\frac{g_{r}}{\mu_{0} A_{r}}
$$

와 같이 표현된다. $l_{m r}$ 과 $A_{m r}$ 은 반경방향 $\mathrm{HMB}$ 의 영구자석 길이와 단면적이고, $g_{r}$ 은 공극의 크기, $A_{r}$ 은 코어 하나의 단면적이다. 그러면, 공극에서의 바 이어스 자속밀도 $B$ 는 식 (13)과 같이 유도된다.

$$
B=\frac{\phi_{c}}{A_{r}}=B_{\mathrm{r}} \cdot \frac{1}{\frac{2 g_{r}}{l_{m r}}+\frac{4 A_{r}}{A_{m r}}}
$$

축 방향 $\mathrm{HMB}$ 에서와 마찬가지로 바이어스 자속 밀도가 약 $0.5 \mathrm{~T}$ 가 되도록 변수들을 설정한다. 먼저, 공극은 $0.8 \mathrm{~mm}$ 로 하였고, 영구자석의 높이는 상하 층 코어 사이의 코일 권선 공간을 고려하여 $18 \mathrm{~mm}$ 로 정하였다. 영구자석의 높이가 너무 크면 상하 코 어 간격이 증가하여 축의 기울어짐 거동의 제어에 불리하고, 너무 작으면 상하 코어 사이의 누설 자속 이 증가한다. 코어의 단면적 $A_{r}$ 은 반경방향 최대 전 자기력과 다음과 같은 관계가 있다.

$$
F_{r, \text { max }}=\frac{\left(B_{\max }\right)^{2}\left(2 A_{r}\right)}{2 \mu_{0}} \approx 1.146 \times 10^{6} A_{r}
$$

반경방향 최대 전자기력은 회전체의 동적 부하를 고려하여 선정한다. 즉, 회전속도 $12,000 \mathrm{rpm}$ 에서 
밸런싱 등급을 $\mathrm{G} 6.3$ 으로 가정할 때, 불균형량은 약 $5 \mathrm{gmm} / \mathrm{kg}$ 이므로, 불균형력은 약 $1,100 \mathrm{~N}$ 이다. 그러 므로 하나의 반경방향 $\mathrm{HMB}$ 에서 요구되는 최대 전 자 기력은 $550 \mathrm{~N}$ 이상이면 되지만, 해석 오차와 안 전율을 고려하여 그 두 배 정도로 하였다. 설계된 $A_{r}$ 은 $924.25 \mathrm{~mm}^{2}$ 이다. 그러면 식 (13)에서 $B \gg 0.5$ $\mathrm{T}$ 이기 위해 $A_{m r}$ 은 $1,472 \mathrm{~mm}^{2}$ 로 계산된다. 그러나 이 설계값에 대해서 $\mathrm{FEM}$ 해석을 수행한 결과, 공 극 자속밀도는 약 $0.29 \mathrm{~T}$ 가 얻어졌다. 이 오차는 상 하 코어 사이의 공간을 통한 자속 누설이 주원인일 것으로 판단된다. 그래서 $A_{m r}$ 을 증가시키면서 $\mathrm{FEM}$ 해석을 수행하여, 공극에서의 바이어스 자속밀도 $\mathrm{B}$ 가 대략 $0.5 \mathrm{~T}$ 가 되는 $A_{m r}$ 을 선택하였다. 최종 결정 된 반경방향 $\mathrm{HMB}$ 에 대한 설계변수들을 Table 2에 정리하였다. Fig. 9는 최종 결정된 설계 안에 대한 3 차원 FEM 해석 결과로서, (a)는 영구자석 주변의 공간으로 누설 자속이 통과하고 있음을 보여주고, (b)는 원주 방향으로 공극의 자속밀도 분포를 도시 한 그림이다. 네 개의 코어에서 동일하게 $0.503 \mathrm{~T}$ 의 바이어스 자속밀도가 발생함을 알 수 있다. 참고로, 식 (13)으로부터 구한 값은 $0.858 \mathrm{~T}$ 로서 해석값과 비교할 때 여전히 큰 오차는 존재한다.

한편, Fig. 8(b)는 반경 방향 전자석을 포함하는 자기회로이고, 여기서 공극에서의 제어 자속밀도 $B_{r c}$ 는

$$
B_{r c}=\frac{\mu_{0} N_{r} I_{r}}{g_{r}}
$$

으로 표현된다. 앞 절에서와 유사한 방법으로, $B_{r c}$ 의

Table 2 Specification of radial HMB

\begin{tabular}{|c|c|c|}
\hline \multicolumn{2}{|r|}{ Parameter } & Value \\
\hline \multirow{4}{*}{ PM } & Height(mm) & 18 \\
\hline & Outer dia.(mm) & 148 \\
\hline & Inner dia.(mm) & 134 \\
\hline & Cross-sectional area $\left(\mathrm{mm}^{2}\right)$ & 3100 \\
\hline \multirow{3}{*}{ Stator core } & Outer dia.(mm) & 116 \\
\hline & Thickness(mm) & 20 \\
\hline & Area of one core $\left(\mathrm{mm}^{2}\right)$ & 924.25 \\
\hline \multirow{2}{*}{ Rotor core } & Outer dia.(mm) & 156 \\
\hline & Inner dia.(mm) & 117.6 \\
\hline \multicolumn{2}{|c|}{ Air gap size(mm) } & 0.8 \\
\hline
\end{tabular}

최대값은 반경 방향 최대 변위가 발생하였을 때, 좁 아진 공극에서의 바이어스 자속밀도를 상쇄할 수 있는 수준으로 결정한다. 반경방향 비상 베어링 간 극은 공극의 $1 / 2$ 인 $0.4 \mathrm{~mm}$ 로 하였으므로 최대 변위는 $0.4 \mathrm{~mm}$ 가 되고, 이때의 공극 자속밀도 분포를 $\mathrm{FEM}$ 으로 구하면 Fig. 10과 같다. 그림에서 $A$ 로 표시된

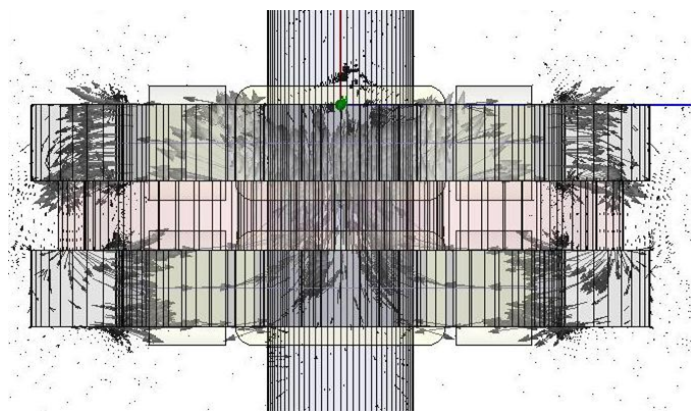

(a)

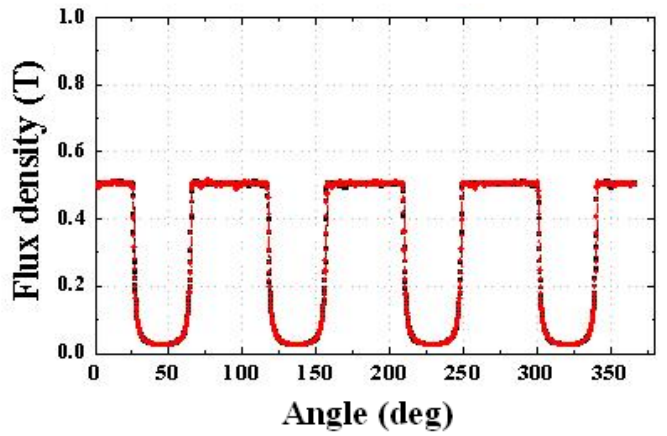

(b)

Fig. 9 (a) Flux density vector plot and (b) circumferential distribution of flux density at the air gap, obtained by FEM

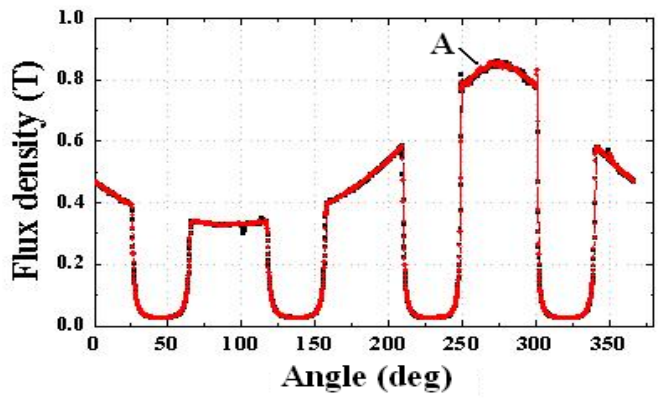

Fig. 10 Circumferential distribution of flux density at the air gap, obtained by FEM, when the rotor moves by $0.4 \mathrm{~mm}$ 
좁아진 공극에서의 평균 자속밀도는 약 $0.825 \mathrm{~T}$ 이 고, 식 (15)로부터 반경 방향 $\mathrm{HMB}$ 의 최대 기자력 $N_{r} I_{r}$ 은 $525 \mathrm{~A} \cdot$ turn로 계산된다. 여기서 권선수 결정 을 위해서는 힘 슬루율을 고려한다. 동적 부하의 주 원인이 불평형력이라면, 요구되는 최대 힘 슬루율은

$$
\left|\frac{d F}{d t}\right|_{\max }=F_{s y n c} \Omega_{\max } \leq \frac{2 B_{s a t}}{\mu_{0} N_{r}} V_{\mathrm{s}}
$$

와 같이 표현되는데, 앞에서 $F_{s y n c}=1,100 \mathrm{~N}$ 으로 가 정했고 회전속도는 $12,000 \mathrm{rpm}$ 이므로, 최대 힘 슬루 율은 $1.38 \mathrm{~N} / \mathrm{msec}$ 로 얻어진다. 식 (16)의 우변에서, 공급 전압과 권선수를 각각 $V_{s}=100 \mathrm{~V}, N_{r}=100$ 으로 하면 위의 관계를 넉넉히 만족함을 알 수 있 다. 따라서 제어 전류 $I_{r}$ 은 $5 \mathrm{~A}$ 로 하였다.

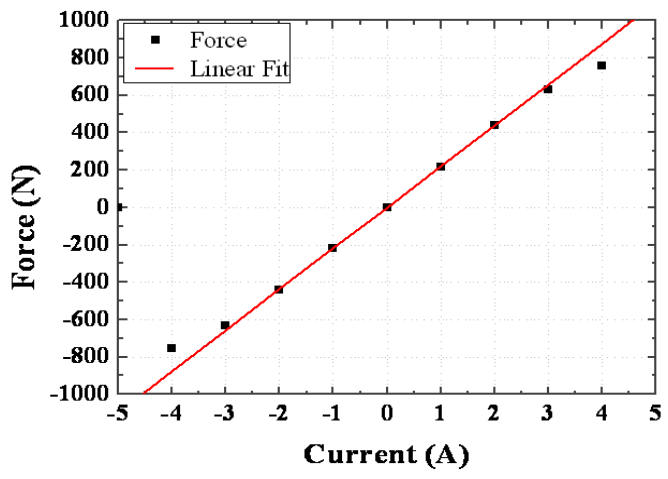

Fig. 11 Variation of magnetic force according to control current at normal state in radial HMB

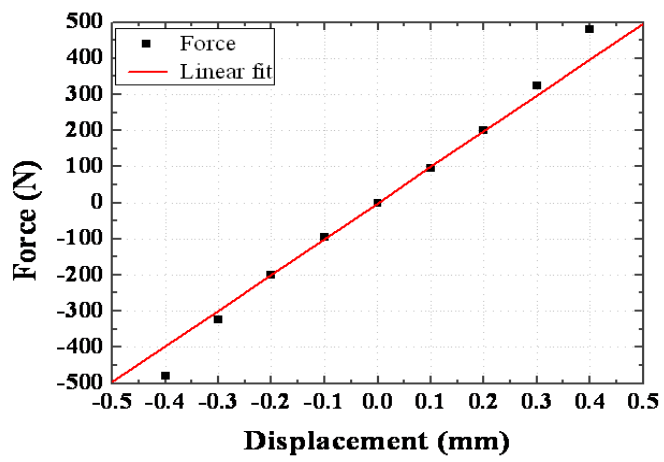

Fig. 12 Variation of magnetic force according to rotor displacement when $I=0 \mathrm{~A}$ in radial HMB

\subsection{FEM 해석에 의한 동특성 예측}

Fig. 11은 전류강성계수를 구하기 위해, 회전자가 정상 상태 위치를 유지하고 있을 때 제어 전류 변 화에 따른 전자기력의 변화를 도시한 것이다. 동작 점 근처에서 근사화한 직선의 기울기인 전류강성계 수는 $219.4 \mathrm{~N} / \mathrm{A}$ 이다. $\mathrm{HMB}$ 에서는 전류와 힘의 관 계는 선형적인 특성을 보여야 하지만, $4 \mathrm{~A}$ 이상 인 가 시 전자기력이 다소 감소한 것은 바이어스 자속 과 제어 자속의 상쇄가 예상대로 이루어지지 않고 하나의 코어 면에서도 경로가 나누어져 두 자속이 교차하는 현상이 발생하였기 때문이다.

Fig. 12는 제어 전류가 인가되지 않은 상태에서 회전체의 반경 방향 변위에 따른 전자기력 변화를 해석한 결과이다. 위치 강성계수는 $0.997 \times 10^{6} \mathrm{~N} / \mathrm{m}$ 로 계산되었다. 축 방향 $\mathrm{HMB}$ 의 경우와 비슷하게, 반경 방향 비상 베어링 간극 $(0.4 \mathrm{~mm})$ 만큼 변위가 발생할 때, 최대 전류 $5 \mathrm{~A}$ 가 인가된다고 가정하면, 피드백 제어기를 포함한 페루프 시스템의 안정된 강성계수는 대략 다음과 같은 값을 갖게 될 것이다.

$$
\begin{aligned}
K_{r} & =219.4 \times \frac{5}{0.4 \times 10^{-3}}-0.997 \times 10^{6} \\
& =1.746 \times 10^{6}(\mathrm{~N} / \mathrm{m})
\end{aligned}
$$

그리고, 반경 방향 $\mathrm{HMB}$ 는 상하 2조로 구성되므 로, 시스템의 병진 모드 주파수는 대략 $25.1 \mathrm{~Hz}$ 근 처가 될 것으로 예상된다. $\mathrm{HMB}$ 의 경우 위치강성계 수 대비 전류강성계수가 종래의 $\mathrm{AMB}$ 에 비해 다소 작아서, 전체 시스템의 강성도 낮게 나타나는 경향 을 확인할 수 있다.

\section{4. 결 론}

이 논문은 $1 \mathrm{kWh}$ 급 $\mathrm{FESS}$ 를 위한 축 방향과 반 경 방향의 $\mathrm{HMB}$ 의 구조 및 제어 원리를 제시하고 구체적인 설계 방법을 소개하였다. 특히, 축 방향 $\mathrm{HMB}$ 의 영구자석이 회전체의 자중 지지 역할도 함 께 수행하는 구조는 시스템의 소형화에 크게 기여 하는 장점이 있다. 한편, 영구자석을 포함하는 자기 회로 해석 결과는 비록 작지 않은 오차를 가지고 있으나, FEM 해석에 앞서 시스템 관점에서의 설계 가이드를 제공하는 유용한 수단임을 밝혔고, 설계된 $\mathrm{HMB}$ 에 대한 $\mathrm{FEM}$ 해석 결과로부터 시스템의 동특 
성 계수들을 예측하였다.

이 논문에서 소개되지는 않았지만, 앞의 방법으로 설계된 $\mathrm{HMB}$ 의 성능 검증을 위하여 $\mathrm{FESS}$ 시작품 을 제작하였고, 2010년 4월 현재, $\mathrm{PD}$ 제어기를 적 용하여 안정된 자기부상에 성공하였다. 이와 같은 내 용을 포함한, 보다 자세한 제어기 설계와 실험적 검 증 결과는 후속 논문에서 소개하기로 한다. 참고로, 제작된 시작품은 5 자유도 부상 상태에서 약 $40 \mathrm{~W}$ 의 전력을 소모하였는데, 만약 공급 전압이 $100 \mathrm{~V}$ 이고 $2 \mathrm{~A}$ 정도의 바이어스 전류를 갖는 일반적인 $\mathrm{AMB}$ 경우라면, 소모전력은 $2 \mathrm{~kW}$ 에 이를 것이다. 이는 저 전력소모 자기부상이라는 $\mathrm{HMB}$ 의 특성을 잘 보 여주는 결과이다.

\section{후 기}

이 논문은 전력산업연구개발사업의 일환으로 한 국전력공사 전력연구원의 지원을 받아 수행된 연구 결과입니다. 지원에 감사드립니다.

\section{참 고 문 헌}

(1) Allaire, P. E., et al., 1990, "Permanent Magnet
Biased Magnetic Bearings - Design, Construction and Testing," Proceedings of the 2nd Int'l Symp. on Magnetic Bearings, Tokyo, Japan, July 12 14.

(2) Fukata, S. and Yutani, K., 1998, "Characteristics of Electromagnetic Systems of Magnetic Bearings Biased with Permanent Magnets," Proceedings of the 6th Int'l Symp. on Magnetic Bearings, USA, August 5 7.

(3) No, S. K., Kim, J. S. and Choi, S. K., 1995, "PM/EM Hybrid Magnetic Bearing System for Flywheel Energy System," Proceedings of the KSAS Annual Fall Conference, pp. 360 363.

(4) Choi, S. K., Kim, Y. C., Yoon, K. C. and Kyung, J. H., 1998, "Rotor Dynamic Design and Analysis of the Rotor-bearing System of a $500 \mathrm{Wh}$ Flywheel Energy Storage Device," Transactions of the Korean Society for Noise and Vibration Engineering, Vol. 8, No. 1, pp. 81 86.

(5) Kim, S.-J. and Okada, Y., 2001, "A Small Disk-type Hybrid Self-bearing Motor," Transactions of the Korean Society for Noise and Vibration Engineering, Vol. 11, No. 8, pp. 338 348. 